\title{
Las relaciones argentino-uruguayas: la cuestión de las "papeleras"
}

BEATRIZ CAROLINA CRISORIO*

\begin{abstract}
Resumo: A instalação de fábricas estrangeiras produtoras, em grande escala, de pasta de celulose para a exportação trouxe dificultades para as relações entre o Uruguai e a Argentina, devido às reclamações daqueles setores que se consideram prejudicados por essa atividade. A questão se tornou evidente a partir da instalação da Botnia Fray Bentos, no curso do rio Uruguai, tema que levou os dois países a apresentar demandas em vários foros e recorrer à Corte Penal Internacional de Haya.

Abstract: The recent installation of foreign factories producers of cellulose paste have tensioned the diplomatic relations between Argentina and Uruguay, this recent event is happening because some sectors of the economy are feeling damaged by this new industrial activity. This issue is in evidence since the construction of the Botnia Frey Bentos factory, on the shore of the Uruguay River, which made both countries to present their case in international foruns, including the International Court of Arbitration in The Hague.
\end{abstract}

Palavras-chave: Argentina. Uruguai. Pasta de celulose.

Key words: Argentina. Uruguay. Cellulose paste.

\section{Introducción}

Tras la irrupción de los conquistadores europeos en los escenarios sudamericanos, y cuando las dificultades y obstáculos dejaron paso al afianzamiento del poder castellano en la región, Buenos Aires se convirtió en una pequeña ciudad periférica del Virreinato del Río de la Plata. En el siglo XVII, cuando las coronas castellana y lusitana volvieron a separarse, en la orilla oriental los portugueses fundaron Colonia del Sacramento, que fue cambiando de manos hasta quedar definitivamente bajo poder hispano. Cuando estalló la Revolución Francesa y se sucedieron las guerras napoleónicas, en ambas márgenes del Río de la Plata emergieron sentimientos libertarios. El oriental José Gervasio de Artigas lideró a las fuerzas que no deseaban la dominación colonial, pero pronto

* Facultad de Ciencias Económicas - Universidad de Buenos Aires.

Estudos Ibero-Americanos, PUCRS, v. XXXIV, n. 1, p. 142-159, junho 2008 
dejaron en claro que no querían participar de un proyecto político donde los intereses de una parte importante de la población de esa región no fueran escuchados (E. Azcuy Ameguino, 1993). Se puede afirmar entonces que, desde el principio, las relaciones entre las nuevas naciones en formación pusieron de manifiesto fuerzas de atracción merced a una historia, un idioma y tradiciones en común, como también surgieron obstáculos e intereses encontrados que dificultaron el entendimiento regional.

En la actualidad, el viajero argentino siente esa cercanía cuando ingresa al Uruguay y disfruta del encanto del casco histórico de Colonia - tan orientada al turismo internacional en los últimos años -, del atractivo del litoral atlántico y su elitista Punta del Este, o bien de los apacibles y vibrantes paisajes de la región oriental que recuerdan a los paisajes de la provincia de Entre Ríos. Con el vecino hay estrechos lazos económicos y políticos. Por décadas un volumen significativo de capitales argentinos se ha dirigido al sector bancario y financiero del vecino país.

Por otra parte, Uruguay aceptó conformar MERCOSUR junto a la Argentina, Brasil y Paraguay. Sin embargo, Montevideo no ha renunciado a mostrar, en diversas cuestiones, una política exterior diferenciada de sus socios. Por supuesto que todo proceso de integración presenta dificultades que por momentos parecen insalvables y, generalmente, los principales desencuentros se han producido por cuestiones mayoritariamente económicas. Sin embargo, hay elementos que ponen de manifiesto cuestiones más complejas que la simple compatibilización de las políticas macroeconómicas. En tal sentido podemos señalar la tensión creciente entre los vecinos a partir del anuncio uruguayo de la instalación de pasteras en el curso del río Uruguay frente a la costa argentina. Una creciente y organizada resistencia de un grupo de pobladores de la provincia argentina de Entre Ríos trató de evitar, y luego frenar, la construcción de una planta productora de celulosa por la empresa finlandesa Botnia en la ciudad de Fray Bentos, Departamento de Río Negro, Uruguay. En este breve trabajo haremos un análisis del proceso que va desde la firma del convenio del gobierno uruguayo con esa y otras empresas, autorizando a la instalación de dichas plantas, hasta la puesta en marcha de Botnia a fines de 2007. El desencuentro entre los dos países por la resistencia de grupos de activistas, encabezados por ecologistas, principalmente del lado argentino, hizo crecer la tensión y empujó a Montevideo y Buenos Aires a hacerse acusaciones mutuas. Se 
produjeron cortes de ruta frente a los puentes binacionales, provocando demoras y perjuicios económicos al comercio que se vale del tránsito de camiones, tanto de los procedentes de Chile y del centro y sur de la Argentina, que suelen cruzar por el sur de Entre Ríos hacia Uruguay y Brasil, como de aquellos que realizan el camino inverso. Ambas Cancillerías presentaron reclamos frente a entidades regionales e internacionales en una compulsa que no frenó la construcción y la inauguración de la primera y más importante de las plantas anunciadas. Pero cuando las relaciones bilaterales parecen más encrespadas, surgen instancias de diálogo y apaciguamiento. Es que, a pesar de todo, el comercio entre ambos países ha crecido de modo significativo, lo mismo que el flujo de turistas argentinos, sin contar la colonia de uruguayos que buscaron refugio en la Argentina durante la última dictadura o en años de dificultades económicas, o los argentinos que han elegido vivir en la orilla más tranquila.

Por último, queremos aclarar que, reconociendo que el eje principal del debate en las relaciones bilaterales es el tema de la contaminación ambiental, el presente trabajo no intenta resolver este punto, que es un trabajo para especialistas. Simplemente es un primer acercamiento a la cuestión que está separando a ambos países. Hemos utilizado trascendidos de la prensa, documentos publicados por algunas de las organizaciones ecologistas que presentan batalla al proyecto, como también la documentación publicada por el gobierno de la República Oriental del Uruguay, los informes del Banco Mundial y los de la empresa Botnia. Curiosamente, una parte importante de la información acerca del proyecto y puesta en marcha es la información emanada de la empresa que se expone en los portales de Internet del BM y del ejecutivo uruguayo. Evidentemente, las siguientes cuestiones quedarán abiertas: ¿Es un proyecto que favorece el desarrollo industrial del país hermano, tantas veces reclamado por los sectores proclives a lograr un cambio en la estructura productiva como también de aquellos partidarios de redistribuir la riqueza? ¿Habrá que escuchar a las voces de los ambientalistas que temen por la contaminación del agua, del aire y del impacto a largo plazo merced a la sobre-forestación en detrimento del ecosistema? ¿O finalmente, como sostienen los críticos de la dependencia de nuestros países, esto sólo será un ciclo económico extractivo de recursos que no generará un cambio de la estructura productiva ni favorecerá la instauración de un modelo autosustentable? 


\section{Bajo el signo de Orión ${ }^{1}$}

Si analizamos desde el comienzo el "Proyecto Orión", la primera pregunta que le surge al historiador es por qué se eligió a ese mortal hijo de dioses para denominar el nuevo emprendimiento. Si se buscaba resaltar el tamaño del emprendimiento y el brillo de esa importante constelación, el nombre es acertado, pero si se piensa que el gigante se especializaba en cazar toda clase de fieras, esta figura mítica, sin querer, estaría invocando en alguna medida los temores de los grupos ecologistas que cuestionaron el emplazamiento de esta planta y sus consecuencias negativas para el medioambiente.

El gobierno del ex presidente J. Batlle suscribió convenios para iniciar la construcción de plantas productoras de pasta de celulosa destinada a la fabricación de papel con la empresa finlandesa BOTNIA, la hispana ENCE, y una empresa sueca. Las dos primeras están estrechamente vinculadas, de acuerdo a la documentación presentada por Botnia:

El acuerdo comercial entre BOTNIA y ENCE sigue vigente. Según el acuerdo [de 1997], Ence es agente en España y Reino Unido de los productos de pulpa de Botnia; y Botnia es agente de los productos de Ence en Finlandia (Botnia, 2003).

En marzo de 2002, el Ministro de Comercio Exterior de Finlandia, Jari Vilen, junto a una delegación de empresarios industriales, visitó al país sudamericano y suscribió, con el Ministro Interino de Relaciones Exteriores uruguayo, Guillermo Valles, el Acuerdo Relativo a la Promoción y Protección de Inversiones para

1 Orión uno de los más brillantes hijos de la mitología griega, nació de una visita de tres dioses inmortales: Zeus, Hermes y Poseidón, a Hirieo, rey de Hiria. Satisfechos, le otorgaron el cumplimiento de un deseo. El rey no tenía hijos y deseaba un heredero. Los dioses le pidieron que enterrara el cuero del bovino que habían comido y orinaron encima. A los nueves meses nació el esperado descendiente, a quien el rey bautizó Orión. El gigantesco joven era un gran cazador. Intentando cautivar a Mérope, hija del rey de Quíos, Enopión, "limpió la isla de toda suerte de bestias salvajes". Al ser rechazado, la violó. Para reparar el honor de Enopión, Dionisio durmió a Orión. El vengativo padre le arrancó los ojos aunque el gigante recuperó la vista. Artemisa se enamoró de él, pero acabó matándolo de un flechazo por error, inducida por los celos de su hermano Apolo, o por la mordedura de un escorpión, como revancha del intento de violación de Orión. Tras su muerte, Zeus lo "sumergió en el Hades, donde la sombra del gigante continúa destruyendo bestias salvajes con una maza de bronce". O bien, se dice que terminó en el cielo con áurea armadura y una espada en la mano, acompañado de sus perros de caza (F. Guirand, 1971, p. 202-203). 
intensificar la cooperación económica para mutuo beneficio de ambos países a fin de mantener justas y equitativas condiciones para las inversiones realizadas por una Parte Contratante en el territorio de la otra Parte Contratante, reconociendo, asimismo, que su promoción y protección estimularán las iniciativas comerciales" (MRREEU, 2002).

Hasta ese momento, los vínculos económicos eran esencialmente comerciales, con el intercambio de productos de peletería, madera y carne uruguayos y maquinaria, papel, cartón y automóviles fineses. Con este convenio, vigente por 2 décadas y por los 12 años siguientes, se buscó crear un marco protector para las inversiones finlandesas, lo que despertó algunas voces críticas uruguayas (M. A. Cabrera, 2005).

En julio de 2003, Celulosas de $\mathrm{M}^{\prime}$ Bopicuá SA, empresa uruguaya filial del grupo hispano ENCE, merced a un comunicado de prensa, informó que había presentado un proyecto realizado por la empresa Zoluciona Calidad y Medioambiente a DINAMA, para obtener la Autorización Ambiental Previa para instalarse, de acuerdo a la legislación de 1994, sobre el río Uruguay, en el Departamento de Río Negro; en octubre de ese año, Botnia SA presentó un proyecto para la construcción de una fábrica de celulosa que se establecería muy cerca de Fray Bentos, en ese mismo Departamento, situado levemente al suroeste del proyecto de Ence.

DINAMA catalogó al Proyecto Orión como Categoría C, que corresponde a

proyectos que en su ejecución puedan producir impactos ambientales negativos significativos (aunque se encuentren previstas medidas de prevención o mitigación). Estos proyectos requieren un estudio de impacto ambiental detallado (DINAMA, 2006).

Asimismo, el ente ordenó realizar un estudio (EsIA) sobre el posible impacto del emprendimiento en la región, para poder conseguir autorización (AAP). Por lo cual se elaboraron los informes de la CFI y el OMGI. Finalmente, DINAMA autorizó a Botnia Fray Bentos la zona franca y la construcción de un puerto en Nueva Palmira (22/9/2004). Luego, merced a la auditoría realizada por la $\mathrm{CAO}$, se recomendó mejorar la publicidad de la información correspondiente (DINAMA, 2006; CAO, 2006).

La obra habría de ser financiada por el GBM, que exigió una evaluación:

La decisión de seguir adelante fue basada en un extenso proceso de debida diligencia que incluyó los resultados concluyentes y positivos de un estudio de impacto acumulativo y un análisis posterior del estudio realizado por expertos independientes (el informe Hatfield) (GBM, octubre 2006). 
Sobre la base de este y otros informes, se aprobó el otorgamiento de una importante suma que, según algunos informes, llegaría a 950 millones U\$S, de los cuales 200 se destinarían a la construcción de la planta (Botnia, marzo 2004). También se recurrió a la Agencia Multilateral de Garantía de Inversiones (MIGA, GBM) para brindar un seguro de riesgo político para inversores en la planta Orión.

Esta y otras informaciones surgieron del informe público realizado por la empresa frente a la comunidad. Las principales inquietudes de la población reflejaban la situación socio-económica de los asistentes: la posibilidad de trabajo, el impacto ambiental sobre actividades previas - pesca, agricultura e industria -, turismo, etc. También se pusieron de manifiesto cuestiones relacionadas con el medioambiente y el posible impacto negativo sobre el río y la región.

Botnia reconoció la magnitud del emprendimiento ${ }^{2}$, que efectivamente se ubicó cerca de Fray Bentos, en las cercanías del puente binacional Libertador General San Martín que une esta ciudad con Gualeguaychú (Entre Ríos, Argentina). Durante su construcción se habrían contratado unos 80.000 operarios. A partir de su puesta en marcha hay sólo 300, aunque estaría dando ocupación a más de 2.000 en transporte y silvicultura.

\section{El impacto en las relaciones bilaterales}

Cuando durante 2002 los vecinos de Gualeguaychú se enteraron de que en Uruguay promovían la instauración de esas empresas europeas en su territorio, comenzaron a organizarse, temerosos de la contaminación de las aguas del río por la dimensión de los futuros emprendimientos. Si bien estas plantas están orientadas a la producción de pasta de celulosa y no de papel, la resistencia popular levantó el lema "no a las papeleras". Recordemos que ya antes de la desastrosa caída del gobierno argentino (Fernando De la Rúa, diciembre de 2001), además de las tradicionales formas de organización política y sindical, surgieron nuevas organizaciones como respuesta a la implementación de las políticas neoliberales impuestas sin anestesia por Carlos S. Menem

2 En Finlandia hay 5 establecimientos produciendo 550.000 tns./año cada uno, utilizando coníferas extraídas de bosques protegidos, mientras que en Uruguay se utiliza el monocultivo de eucaliptus, no originario de América, con el objetivo de alcanzar el millón de tns./año. 
(1989/1999). En tal sentido, el cuestionamiento a la posible contaminación ambiental encontró rápida respuesta en algunos sectores de la provincia de Entre Ríos, que junto a las organizaciones uruguayas comenzaron a movilizarse.

Esto produjo malestar entre Montevideo y Buenos Aires. El presidente uruguayo J. Batlle realizó algunas afirmaciones que fueron consideradas ofensivas por su par argentino, E. Duhalde. El presidente oriental se apresuró a descomprimir la situación, aunque las relaciones se distanciaron. Al llegar algunos rumores de que se buscaba el financiamiento en instituciones internacionales, el gobierno argentino llevó su inquietud al seno de la CARU, comisión mixta del río Uruguay establecida a partir del Tratado de 1975 entre ambas naciones para administrar el uso conjunto de esa fuente fluvial.

En 2004 ambos gobiernos suscribieron un acuerdo para establecer un control compartido sobre la construcción de las plantas pasteras. Sin embargo, la resistencia en Gualeguaychú no cejó, y el nuevo presidente argentino, Néstor Kirchner, mostró cierta predisposición a escuchar los reclamos; por ello, representantes de la Asamblea Ciudadana Ambiental de Gualeguaychú fueron recibidos por el presidente y el Canciller, Rafael Bielsa.

Paralelamente los asambleístas consideraron que tenían que realizar acciones que pusieran mejor en evidencia su lema "no a las papeleras", y decidieron comenzar a cortar las rutas del MERCOSUR - los puentes binacionales que unen la Argentina y Uruguay son el Libertador General San Martín (Gualeguaychú, Fray Bentos), José Gervasio de Artigas (Colón, Paysandú) y Salto Grande (Concordia, Salto).

Cuando asumió Tabaré Vázquez, las expectativas de que se suspendiera la obra fueron defraudadas y, frente a la presión de los asambleístas, el gobierno argentino realizó una presentación ante la Corte Penal Internacional de la Haya (2005), reclamando por el incumplimiento del Tratado el río Uruguay (1975). En el mes de abril, unos 30.000 manifestantes de Gualeguaychú cruzaron el puente hacia Fray Bentos. En el mes de mayo, se produjo un acercamiento entre los gobiernos de ambos países, conformándose el Grupo Técnico Bilateral de Alto Nivel (GTAN), estableciendo un plazo de 180 días para realizar un estudio sobre el posible impacto ambiental. De todos modos, la tensión continuó creciendo, y en octubre llamaron a sus representantes diplomáticos para que retornaran a sus países. 
Los asambleístas, por su parte, decidieron hacer sentir su fuerte resistencia, cortando el puente internacional durante un mes y medio. A su vez, el gobierno argentino, deseoso de frenar la construcción de un nuevo puerto, tras fracasar en sus reclamos frente a la CARU, presentó una queja frente a su par uruguayo.

En enero de 2006, trascendió el anuncio de que, además de ENCE y Botnia, se establecería otra pastera, la sueca Stora Enso. Paralelamente, el Canciller uruguayo declaraba que la Argentina en realidad no quería negociar y que el diálogo estaba roto (Clarín, 29/01/2006).

En marzo, en el encuentro de ambos presidentes en Chile, trascendió que se suspendería la construcción de Botnia a cambio del levantamiento de los cortes. Sin embargo, Tabaré Vázquez negó que hubiera ningún compromiso y se suspendió una reunión en Colonia.

En junio, ambos países presentaron reclamos ante la Haya. Argentina solicitando que el gobierno de Uruguay detuviera la construcción de las pasteras sobre el río, y éste, exigiendo que el gobierno argentino tomara recaudos para frenar los cortes de ruta, aduciendo un gran daño económico.

El tribunal, en julio de 2006, estableció que la construcción podía continuar, aunque se dejaba lugar a posibles reclamos argentinos. Esto fue recibido con euforia por Uruguay, pero también por la Argentina. Luego, la Haya desestimó los reclamos uruguayos respecto de los cortes de ruta (enero 2007), lo cual fue muy bien recibido por el gobierno argentino.

Uruguay presentó sus quejas en MERCOSUR, pero se sostuvo que los mecanismos legales no estaban lo suficientemente desarrollados como para intervenir. También se sostuvo que era invasivo que Uruguay pidiera que se reprimiera a los asambleístas. A pesar de los esfuerzo de Montevideo para que en la Cumbre de MERCOSUR (Córdoba, julio de 2006) apoyara las pasteras, la iniciativa no prosperó.

Paralelamente, cuando la Argentina presentó su demanda en La Haya, en junio de 2006, ENCE suspendió la construcción de su planta. En noviembre de ese año, durante la XVI Cumbre Iberoamericana convocada en Montevideo, en un clima tenso el presidente Kirchner pasó brevemente por el evento y le solicitó al Rey Juan Carlos de Borbón una mediación. Por ello, la corona nombró "facilitador" a Juan Antonio Yáñez, quien negoció la relocalización de la planta en otra área para disminuir el impacto 
ambiental sobre el río Uruguay. Aunque en diciembre se iniciaron las gestiones, el acercamiento de las partes resultó sumamente dificultoso. En mayo de 2007 ambas delegaciones se reunieron en Nueva York gracias a sus gestiones. Allí, la Argentina volvió a solicitar que se relocalizara la fábrica.

En agosto, Botnia estuvo prácticamente terminada y comenzó a funcionar "a prueba", recalentándose las relaciones bilaterales, a la vez creando un clima caldeado entre los vecinos de Gualeguaychú y el presidente argentino, puesto que los asambleístas interpretaron que el gobierno se resignaría a la inauguración de las plantas. Las cosas se calmaron cuando el presidente Kirchner aclaró que la Argentina mantendría el reclamo de relocalización de la planta, pero las relaciones bilaterales se mantuvieron tensas.

Cuando asumió Cristina Fernández de Kirchner en diciembre de 2007, Tabaré Vázquez viajó a Buenos Aires y ambos se mostraron afectuosos, aunque la mandataria hizo referencia al conflicto. En su discurso, la presidenta sostuvo:

Quiero también agradecer la presencia del Presidente de la República Oriental del Uruguay, el doctor Tabaré Vázquez. Quiero decirle con toda la sinceridad que siempre he tenido en toda mi práctica política, que no va a tener de esta Presidenta un solo gesto que profundice las diferencias que tenemos, pero también con la misma sinceridad quiero decirle que esta situación que hoy atravesamos no nos es imputable. Porque más allá de medidas que muchas veces podemos no compartir, lo cierto es que nosotros nos hemos presentado en la Corte Internacional de La Haya porque se ha violado el Tratado del Río Uruguay al instalar las pasteras.

Este y no otro es el conflicto; resituar el conflicto requiere también un ejercicio de sinceridad por parte de todos nosotros que no significa ahondar la diferencia; simplemente saber cuál es la diferencia para darle gobernabilidad a esa conflictividad hasta tanto resuelva como corresponde a los Estados de derecho el Tribunal Jurídico Internacional que ambos pactamos en el caso de controversias. Esta es hoy la situación pero sepan compatriotas del Uruguay, de la Patria Grande, que lo sentimos los argentinos y lo vamos a sentir siempre nuestros hermanos. Que de esto no haya ninguna duda (MDRA, 10/12/2007).

En Uruguay, las afirmaciones de la nueva presidenta no fueron bien recibidas, a pesar de la falta de declaraciones del gobierno uruguayo. 
Para concluir este breve resumen, conviene destacar que las relaciones no se han recompuesto en el tema Botnia, aunque hay otros aspectos de las relaciones que se muestran como un acercamiento positivo de ambos socios mercosureños.

\section{Cuestiones pendientes ¿y después?}

Esta problemática deja varios temas abiertos. En primer lugar, por el momento resulta impensable que Botnia sea desactivada, a menos que se compruebe fehacientemente que su actividad es dañina para el ecosistema. Ya en mazo de 2006 se realizó, en la Universidad de Buenos Aires, un encuentro en el cual David González, químico de la Universidad de la República del Uruguay, sostenía que era necesario invertir aproximadamente un millón de dólares para medir de manera certera la producción de dioxinas del método kraft. En el mismo sentido, Jorge Etcharrán, químico de la Universidad Tecnológica Nacional, afirmó que ese era uno de los mejores métodos, pero no evitaría la contaminación del río; el biólogo de la UBA Claudio Daniele puso el acento en la necesidad de garantizar la transparencia de los mecanismos de control (Clarín, marzo 2006).

Asimismo, la Facultad de Ciencias de la Universidad de la República (Uruguay) realizó un estudio en el que afirmó, entre otras cosas, que:

El Río Uruguay es uno de los recursos hídricos de uso múltiple más importante a escala nacional. El mismo es utilizado para la generación de energía eléctrica, abastecimiento de agua potable, regadío, procesos industriales, pesca artesanal y recreación. La instalación de dos industrias de celulosa con proceso Kraft ECF, las cuales producirán una descarga al Río Uruguay de $125.000 \mathrm{~m} 3 /$ día de efluentes líquidos, conlleva la necesidad de implementar un adecuado programa de control y monitoreo que permita evaluar los potenciales efectos.

[...]. Con relación a los efectos sobre el suelo, numerosos estudios comparativos indican una fuerte acidificación de los suelos bajo forestación con respecto a los de pastizal. Acompañando los efectos sobre el $\mathrm{pH}$, la forestación reduce la concentración de ciertas bases como el calcio, magnesio y potasio, mientras que aumenta la cantidad de sodio intercambiable y la concentración de aluminio del suelo. Muchos de los cambios químicos (acidificación, salinización, pérdida de nutrientes) son irreversibles y comprometen seriamente la fertilidad y, por lo tanto, el potencial productivo de los suelos. Por otra parte, los pastizales naturales albergan el $80 \%$ de la diversidad 
de especies vegetales del Uruguay y una alta riqueza de fauna asociada. La sustitución de la cobertura vegetal por una única especie, conlleva una severa modificación de las tramas tróficas y pérdida de información ecosistémica y genética, además de la aparición de especies, mayoritariamente exóticas, que se comportan como invasoras (FC, URU; 2006).

Paralelamente, sostenía que habría que tomar en cuenta la gran diversidad de químicos que se han estado vertiendo en su curso antes de la puesta en marcha de las plantas con un impacto considerable:

En términos generales, los efluentes contienen elevadas cantidades de sólidos en suspensión (orgánicos e inorgánicos), nitrógeno y fósforo. Los procesos de blanqueo libres de cloro elemental como los propuestos por Botnia y ENCE, producen una amplia gama de compuestos cuya estructura química es similar a hormonas sexuales de peces. Sus efectos son mayoritariamente conocidos a nivel molecular o a nivel de individuo en organismos acuáticos. Estos compuestos (disruptores endócrinos) son derivados de hormonas vegetales o son producto de la degradación de materiales no celulósicos de la madera e inducen alteraciones en el funcionamiento hepático como resultado de los procesos de detoxificación que se llevan a cabo en el hígado. Existen numerosos estudios que analizan las respuestas de los peces y otros organismos acuáticos a la descarga de efluentes de las plantas de celulosa sobre los cuerpos de agua. Investigaciones de campo y de laboratorio han reportado importantes cambios en la fisiología reproductiva de los organismos acuáticos como la masculinización, retardo en la madurez sexual, alteraciones en la fecundidad y en la viabilidad de los huevos y cambios en la proporción de sexos de los embriones. Los escasos estudios realizados en organismos terrestres han demostrado efectos importantes como reducción en el peso de los testículos, decremento del esperma total y movilidad de espermatozoides, particularmente en mamíferos expuestos al consumo del agua de los efluentes.

Los estudios de los efectos a otros niveles son recientes y escasos. Las respuestas a nivel comunitario y ecosistémico indican un aumento en la producción primaria (vegetal) asociada a la mayor disponibilidad de nutrientes. Este enriquecimiento puede estimular, en una primera fase, un aumento de la biomasa e inclusive una mayor diversidad. Sin embargo, un enriquecimiento excesivo tiene efectos nocivos sobre la biota con disminución de los niveles de oxígeno y explosiones demográficas de organismos que pueden generar toxicidad en el medio. Esto implica riesgos para la salud y costos incrementados en la potabilización de las aguas para consumo humano (FC, URU; 2006). 
Este informe molestó a las autoridades uruguayas, tal como registra Radio Mundo Real de Uruguay:

Este documento generó diversas respuestas desde las autoridades ambientales del gobierno uruguayo, que cuestionaron el hecho [de] que dicho informe se presentara en este momento en el cual Uruguay y Argentina dirimen esta situación en la Corte Internacional de La Haya. El Ministro de Medio Ambiente de Uruguay, Mariano Arana, manifestó que el documento es "una acumulación increíblemente numerosa de bibliografía extranjera, de apreciaciones personales y de dudas", relativizando el rigor científico del trabajo.

El subsecretario del Ministerio, Jaime Igorra, también relativizó de alguna forma la seriedad del informe alegando que si no se presentaban pruebas, solamente serían "conjeturas". Ambas respuestas se apegan a la actitud adoptada por el gobierno en todo lo relacionado con el tema de las plantas de celulosa, de dudar y menoscabar cualquier tipo de argumento o estudio que alerte sobre los efectos de estos emprendimientos (Radio El mundo real, 2006).

Una de las ONG más activas del Uruguay ha sido Guayubira, que no sólo ha publicado información crítica acerca de la política gubernamental uruguaya, sino que ha buscado coordinar sus acciones con entidades argentinas.

Entre las cuestiones que más destacan esta organización y otros grupos ambientalistas podemos citar:

1. Las críticas al gobierno uruguayo por continuar impulsando el monocultivo de eucaliptus, especie no originaria, que impacta negativamente en el ecosistema, en detrimento de la flora y fauna autóctonas.

2. Las críticas al gobierno del presidente Néstor Kirchner y al gobierno de Entre Ríos por no llevar puertas adentro una política de protección ambiental adecuada, permitiendo actividades con técnicas altamente contaminantes como la indiscriminada explotación de los bosques en varias regiones, como la provincia de Misiones, de Salta, y otras.; la producción de papel; la producción de oro, donde se utiliza cianuro; el cultivo de la soja transgénica; etc.

3. El avance de la concentración y extranjerización de tierras vinculadas a la forestación:

El 11 de febrero [de 2008] se hizo público el Informe Ambiental Resumen para la instalación de la fábrica de celulosa de ENCE en Colonia. Ello hizo posible que se conocieran las cifras más recientes en cuanto al área de tierra en poder de esta empresa. Al respecto el 
informe dice que: "la filial forestal de ENCE en Uruguay, EUFORES, dispone de más de $180.000 \mathrm{Ha}$, de las cuales unas 150.000 son de eucalipto, ubicadas en el Litoral, Este y Centro del país".

El enorme crecimiento constatado del área de tierra adquirida por esta empresa durante el último período, nos movió a investigar las cifras actuales de las otras dos grandes empresas forestales extranjeras: Botnia y la norteamericana Weyerhaeuser.

En el caso de Botnia, hallamos la información en un video (en inglés) accesible en la página web de Metsa Botnia. Allí se dice que Forestal Oriental (subsidiaria de Botnia) es propietaria de 156.000 hectáreas, de las cuales 83.000 plantadas con eucalipto y que se planea un total de 120.000 hectáreas plantadas (2). En caso de mantenerse la relación entre área comprada y área forestada, ello significaría compras totales por la cantidad de 225.000 hectáreas.

Con respecto a Weyerhaeuser, en un informe presentado en setiembre de 2007 por esa empresa, se lee que participa "de un joint venture llamado Colonvade S.A. y Los Piques S.A." y que "este emprendimiento en su conjunto cuenta con un total de 127.500 hectáreas en tierras de las cuales 78.520 ha se encuentran forestadas". Pero esa no es toda la tierra en propiedad de esta empresa. El mismo informe dice que "Weyerhaeuser en el año 2004 toma la decisión de instalarse en el país como Weyerhaeuser Uruguay, y como tal se instaló en los departamentos de Cerro Largo, Rivera, Tacuarembó y Treinta y Tres" donde "cuenta hoy con un total de 43.391 ha de tierras" (3). Es decir, que en total contaba (en setiembre 2007) con 170.000 hectáreas.

En resumen, las cifras más recientes (sólo de las tres mayores empresas forestales) dan un total de:

$\begin{array}{ll}\text { Eufores (Ence): } & 180.000 \\ \text { Forestal Oriental (Botnia): } & 156.000 \\ \text { Weyerhaeuser: } & 170.000 \\ \text { TOTAL: } & 506.000\end{array}$

En un país como Uruguay, que cuenta con alrededor de 16 millones de hectáreas de tierras productivas, el hecho de que medio millón de hectáreas estén en manos de tres empresas extranjeras es un hecho que asusta. Además, es probable que al día de hoy esas cifras ya hayan sido superadas, puesto que todas continúan comprando más tierras. A eso se suma la existencia de otras empresas forestales extranjeras (sueco-finlandesas, chilenas, norteamericanas) que también han comprado y están activamente comprando miles de hectáreas de tierras en nuestro país" (Guayubira, 14/2/2008).

4. El avance de la forestación sobre las áreas más fértiles impiden la realización de otras actividades productivas tradicionales, como la ganadería y el trigo, en un momento en que sube la demanda internacional de alimentos, elevando los precios de los 
mismos - algunos sostienen que es por la debilidad del dólar -, encareciendo estos productos en el mercado interno.

5. La falta de confianza en que el método kraft evite el impacto negativo que las dioxinas a largo plazo en el agua, que es luego utilizada en la agricultura y bebida por humanos y animales, favoreciendo el desarrollo de enfermedades cancerígenas.

6. La falta de precisiones en los informes presentados por Botnia y ENCE en cuanto al impacto ambiental negativo.

7. Las suspicacias que pueden despertar la actuación de los organismos de control donde, al entender de estas organizaciones, debería haber más transparencia. Por ejemplo, Guayubira discrepa con DINAMA acerca de la próxima instalación de fábricas de productos químicos, que supuestamente están destinados para la fabricación de abonos, pero que la ONG sospecha que se utilizarán en las pasteras.

8. El impacto del acarreo de madera para alimentar la fábrica, al igual que el transporte de productos tóxicos, en el medioambiente.

9. Existe también preocupación por la contaminación del aire, por el impacto de los requerimientos de energía, de los malos olores, etc.

Amén de estas señalizaciones, otras voces han apuntado al tipo de emprendimiento que refuerza la dependencia del país, con grandes inversiones de empresas extranjeras, favoreciendo la trasnacionalización de los recursos naturales y, por ende, de la economía. En otras palabras, cuestionan este tipo de inversiones, que no favorecen un cambio en las estructuras productivas que permitan encaminar al país hacia un modelo económico autosustentable.

Asimismo, recordemos que, de un lado, ven con malos ojos los cortes de los puentes internacionales, y algunos vecinos de Fray Bentos sostienen que la gran contaminadora de la región es la Argentina y no Uruguay.

Del otro lado, ciertos grupos ambientalistas encabezados por Gualeguaychú prometen continuar su lucha. Es más, ante la supuesta sugerencia de la presidenta argentina de que habría que acatar el fallo de la Haya, fuera cual fuera, prometieron seguir combatiendo hasta la erradicación total de las papeleras.

Convendría pensar, en cambio, que en lugar de entrar a un callejón sin salida, deberían hacerse esfuerzos mucho más serios para lograr el entendimiento entre ambos países y en la región, puesto que es un secreto a voces que, empezando por los grandes 
países industrializados como Estados Unidos, hay muchísimos países en el globo que no cumplen con el Protocolo de Kyoto (1997), y el cono sur no es una excepción.

También se debería trabajar en alternativas de integración regional que no sólo favorezcan un mayor crecimiento económico, sino que apunten a un mejor desarrollo de las diferentes regiones dentro de cada uno de nuestros países y entre las naciones del Cono Sur, apoyando la implementación de políticas redistributivas que atiendan a la deuda social sin hipotecar el futuro de las nuevas generaciones.

\section{Fuentes}

\section{Referencias}

Azcuy Ameghino, Eduardo. Historia de Artigas y la independencia argentina. Montevideo: Ed. Banda Oriental, 1993.

Botnia: "Respuesta a las preguntas realizadas en el 1er Foro Público". Uruguay. 2 de diciembre de 2003.

Botnia: "Respuesta a las preguntas realizadas en el 2do Foro Público". Uruguay. 2 de marzo de 2004.

Botnia: "Estudio del Impacto Socio-económico del Proyecto Planta de Celulosa Botnia S.A. en Uruguay Preparado para Metsä-Botnia. Resumen ejecutivo", Junio, 2004.

Botnia "Disponibilidad de madera en Uruguay y su flujo hacia Fray Bentos. Seminario Científico". Botnia Marzo 2004.

Botnia: "Evaluación del Impacto Ambiental. Presentación". Botnia, 14.2.2005. Cabrera, M. A.: “El Escándalo de Botnia". Sol y Luna Nº 84. Abril/Mayo. 2005, en Espacio Latino: http:/ / letras-uruguay.espaciolatino.com.

CAO: "Auditoría de la Diligencia Debida de la CFI y del OMGI en dos Plantas de Celulosa en Uruguay. Informe Final", 22 de febrero de 2006.

Celulosas de M' Bopicuá: Proyecto "Celulosas de M' Bopicuá". Public Consultation and Disclosure Plan, 15 de julio 2005.

CFI: "Hoja Informativa del Proyecto Orión - Primera Revisión", 10 de agosto de 2004.

CFI: "Hoja Informativa del Proyecto CMB - Primera Revisión", 15 de diciembre de 2004

DINAMA: “Actualización de la información sobre el proceso de Autorización Ambiental de las Plantas de Celulosa, al 26 de abril de 2006". MVOTMA.

Facultad de Ciencias, Universidad de la República de Uruguay: "Síntesis de los efectos ambientales de las plantas de celulosa y del modelo forestal en Uruguay solicitado por el Consejo de la Facultad de Ciencias a los docentes Daniel Canario, Néstor Mazzeo y Gabriela Eguren (Maestría en Ciencias Ambientales), Claudia Rodríguez y Alice Altesor (Depto. de Ecología), Ricardo Cayssials y Marcel Achkar (Depto. de Geografía). Resolución Nro. 78 del 13/03/2006". 
Faroppa, Carlos y Annala, Kaisu: "Informe ambiental. Resumen", 2 de diciembre de 2005. Botnia.

GBM: "El Grupo del Banco Mundial buscará la aprobación para la planta de celulosa Orión en Uruguay". Grupo Banco Mundial. Washington, 17 octubre 2006.

Guayubira: "Banco Mundial: la decisión de financiar plantas de celulosa aún no ha sido tomada". Comunicado de prensa - 24 de enero de 2006.

Guayubira: "Guayubira entrega al gobierno estudio que contradice afirmaciones de empresas de celulosa". Comunicado de prensa - 18 de enero de 2006.

Guayubira: "Fábricas de celulosa: ciudadano finlandés desmitifica la industria de su país". Comunicado de prensa - 7 de febrero de 2006.

Guayubira: "Guayubira manifiesta su oposición al financiamiento del Banco Mundial a fábricas de celulosa". Comunicado de Prensa - 13 de febrero de 2006.

Guayubira: "Guayubira fundamenta por qué se negó a participar en consulta del Banco Mundial sobre fábricas de celulosa". Comunicado de prensa 15 de febrero 2006.

Guayubira: "Ambientalistas de Uruguay y Entre Ríos piden gestos a ambos gobiernos". Comunicado de prensa - marzo de 2006.

Guayubira: "Nuevo informe del Banco Mundial: El borrador de impacto acumulado de las plantas de celulosaera realmente eso: un (mal) borrador". Comunicado de prensa 18 de abril de 2006.

Guayubira: “La forestación copó los campos arenosos, afectando gravemente el ciclo ganadero". Comunicado de prensa - 30 de junio de 2006

Guayubira: "Plantas de celulosa de tecnología finlandesa generan protestas en tres regiones de Chile". Comunicado de prensa - 27 de octubre de 2006.

Guayubira: Declaración Red Socioambiental. "Organizaciones uruguayas y argentinas buscan restablecer los lazos culturales y la unión entre ambos países contra un modelo productivo que está arrasando con nuestros recursos". Comunicado de prensa - 26 de abril de 2007.

Guayubira: "Iniciativa nacional por la suspensión de la forestación." Comunicado de prensa - 8 de mayo de 2007.

Guayubira: "Organizaciones piden información en Uruguay sobre solicitud de ENCE para operar en zona franca". Comunicado de prensa - 23 de mayo de 2007.

Guayubira: "El vínculo entre el conflicto con ISUSA y la fábrica de Botnia". Comunicado de prensa - 13 de junio de 2007.

Guayubira: "Tabaré Vázquez en inauguración de puerto de Botnia: un triste día para el país". Comunicado de prensa - 29 de agosto de 2007.

Guayubira: "El Uruguay celulósico: gobierno y trabajadores opinan distinto". Comunicado de prensa - 24 de septiembre 2007.

Guayubira: "Avanza concentración y extranjerización de tierras vinculadas a la forestación: ¿No será hora de decir basta?" Comunicado de prensa - 14 de febrero de 2008.

Guirand, Félix: Mitología general, Editorial labor SA. Barcelona. 1971.

Informe Hatfield Consultants Ltd: "Asunto: Estudio de Impacto Acumulativo final para las plantas de celulosa de Uruguay - Evaluación del panel experto". 14 de octubre de 2006. 
Ministerio de Relaciones Exteriores de la República Oriental del Uruguay (MRREEU): Acuerdo Sobre Inversiones entre Uruguay y Finlandia. Junio 2002.

Niemelä, Klaus: "Recuperación de químicos en la planta celulosa". KCL (Finnish Pulp and Paper Research Institute). Botnia.

OMGI "Respuesta de la administración del OMGI: verificación por parte de la CAO del cumplimiento del proceso de análisis de la CFI y el OMGI para dos plantas de celulosa en Uruguay". 9 de marzo de 2006.

Orion ESAP: “Uruguay - Orion Pulp Mill: Environmental and Social Action Plan", 3/8/2007. Banco Mundial.

Radio Mundo Real: 4/07/2006.

Tana, Jukka: "Efectos de los efluentes en el medio ambiete acuático" ÅFCelpap. Botnia.

\section{Internet}

Ministerio de Relaciones Exteriores de la República Oriental del Uruguay: http://www.mrree.gub.uy

Parlamento de la República Oriental del Uruguay: http://www.parlamento. gub.uy

Ministerio de Defensa de la República Argentina: http:/ /www.mindef.gov.ar Corporación Financiera Internacional, GBM: http://www.ifc.org

Botnia: http://www.metsabotnia.com

Espacio Latino: http:/ / letras-uruguay.espaciolatino.com

GBM: http://www.bancomundial.org

Asamblea Ciudadana Ambiental de Gualeguaychú: http:/ /www.noalapapelera. com.ar

Grupo Guayubira: http://www.guayubira.org.uy

Red de comunicación ambiental de América Latina y el Caribe: http:// www.redcalc.org

Diarios de la Argentina y Uruguay.

Facultad de Ciencias, Universidad de la República: http:/ / www.fcien.edu.uy Radio Mundo Real: http://www.radiomundoreal.fm

\section{Glosario}

AAP: Solicitud de la Autorización Ambiental Previa.

ACAG: Asamblea Ciudadana Ambiental de Gualeguaychú.

CAF: Consejo Administrativo Forestal.

CAO: Compliance Advisor Ombudsman [Oficina del Asesor en Cumplimiento/ Ombudsman].

CARU: Comisión Administradora del Río Uruguay.

CES: Departamento de Desarrollo Ambiental y Social.

CFI: Corporación Financiera Internacional. También IFC. Esta entidad depende del GBM y su objetivo sería promover el desarrollo sustentable del sector privado en mercados emergentes. 
CIS: Estudio de Impacto Acumulativo.

CMB: Celulosas de $\mathrm{M}^{\prime}$ Bopicuá.

DEIA: División Evaluación de Impacto Ambiental.

DINAMA: Dirección Nacional de Medio Ambiente dependiente del MVOTMA.

ECF: Tratamiento libre de cloro elemental (dióxido de cloro).

ECF-Light: combina ECF + TCF.

EcoMetrix: firma asesora sobre el medio ambiente canadiense independiente convocada por IFC-GBM.

EsIA: Estudio de Impacto Ambiental.

EIA: Evaluaciones de Impacto Ambiental.

FC, URU: Facultad de Ciencias, Universidad de la República del Uruguay.

FOSA: Compañía Forestal Oriental SA.

GBM: Grupo Banco Mundial.

IAR: Informe Ambiental Resumen.

IPPC: Prevención y Control de la Contaminación Integradas de la Unión Europea.

MDRA: Ministerio de Defensa de la República Argentina.

MIAS: Memorandum de Información Ambiental y Social.

MIGA: Agencia Multilateral de Garantía de Inversiones.

MRREEU: Ministerio de Relaciones Exteriores de la República Oriental del Uruguay.

MVOTMA: Ministerio de Vivienda, Ordenamiento Territorial y Medio Ambiente.

OMGI: Organismo Multilateral de Garantía de Inversiones.

Oy Metsä-Botnia Ab: Nombre de la empresa finlandesa que cuya filial en Uruguay se llama Botnia Fray Bentos.

PAA: Plan de Acción Ambiental.

PAAS: Plan de Acción Ambiental y Social.

PSA: Pulpa secada al aire.

PRAS: Procedimientos de Revisión Ambiental y Social.

RECOMA: Red Latinoamericana contra los Monocultivos de Árboles, con 16 países miembros.

TCF: Tratamiento totalmente libre de cloro. 